\title{
Solar Wear Tattoo: New Technology Through the use of Different Material Behaviours
}

\author{
Vanessa da Graça Mendes ${ }^{1}$ and Mario S. Ming Kong ${ }^{2}$ \\ ${ }^{1}$ Faculty of architecture - University of Lisbon - FA-UL 1349-055 Polo Universitário - Alto da Ajuda, Lisboa, Portugal \\ ${ }^{2}$ Faculty of architecture - University of Lisbon Researchers and CIAUD-permanent member of the Research Centre for Architecture, Urban \\ Planning and Design FA-UL, Portugal
}

\begin{abstract}
This study comes within the framework of a $\mathrm{PhD}$ course in Design, which is the continuation of a Masters Degree research in Fashion Design, searching for wardrobe technology and innovation through material behaviour. The intent of this project is to present solutions that promote a new and versatile product allowing for a different kind of aesthetic. This will be achieved through different materials with different behaviours that when put together create an innovative technology thus creating a new practice of body art, through the use of fashionable beachwear created with this technology. This technology allows the transformation of the suntan marks left by female swimwear. This will result in the creation of designs and drawings on the body, using shapes inspired by the Oriental Zodiac Signs, as well as colours drawn from the five elements of Feng Shui, which are also present in the Western Astrological Signs.
\end{abstract}

\section{Introduction}

Material behaviour and its potential for creating unique functions and new types of objects when combined, and its ability for transforming the suntan marks left by the usual bikini or swimsuit, has been one of the main themes and subjects of this research. This allows for new creative boundaries to emerge in body art through textile technology.

\section{Body art and new practices through beachwear}

\subsection{Body art}

Everyday people produce art on the body in a almost unconscious way, working hair, nails and makeup, because these physical interventions aren't usually associated or even called as a from of body art, although all these actions are a part of a body transformation process, metamorphosing the projected exterior appearance, communicating a set of feelings and values as a part of mans natural social instincts and behaviours. [1]

Focusing on a specific type of body art, tattoo, especially temporary tattoo, it already exists in the form of a practice called Mehdi. [2] This practice is essentially the art of painting a body with henna (Lawsonia Inermis in Latin [3]), an Egyptian plant with a strong characteristic smell. Its leafs and flowers, after dried up, are grinded into dust, mixed with water, lemon juice and some drops of kerosene to create a paste used to make a natural skin dye. [2]

\subsection{New practice through beachwear}

Beachwear originally existed to allow water-sport fans to go to the beach to watch this kind of competitions. [4] Last century, in the last mid 20's, Patou was one of the big fashion creators to conceive such outfits suitable for beach practice. These cloths were made for sportive woman. Mainly, these outfits consisted in short dresses made from different materials, with soft coats to match, which were highly in vogue at that decade.

The main public figure iconic enough to transform fashion beachwear into a body art practice/body cult was Coco Chanel. In the same decade that Patou fashion was in vogue, Chanel practiced outdoor spots often, becoming one of the first women to appear in public with a suntan. [5]

This information makes clear that, since then, suntans and beach practice became a relatively recent, new form of body art in Western fashion.

\section{Harmonious beachwear through Feng Shui logic}

\subsection{Observation of the natural elements}

Pushing the envelope of new body art forms is not easy and, in this case, it would not have been possible without applying Feng Shui logic. 
Western people call it intuition; in Eastern culture that intuition is defined by guide lines based on the logic of nature, which can be acquired by observation of the natural interactions between the various natural elements.

That natural observation is the key. For that reason, Feng Shui is applied as a main theme. It is the concept that gave birth to the hole, extending its principles not only to the choice of materials, but to colour choice and combinations as well, so that it is possible for the users and observers to have a functional and harmonious beachwear experience. [4]

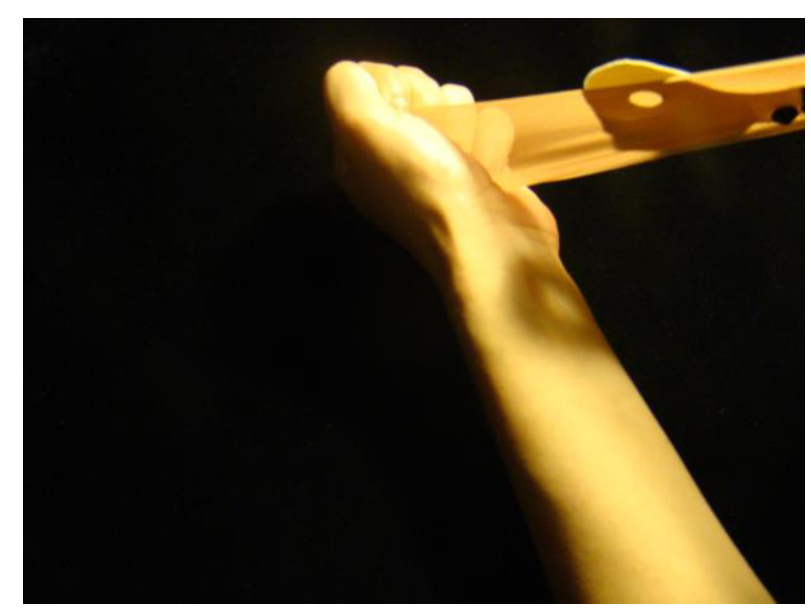

Figure 1. Feng Shui logic. - The observation of the natural elements interacting with materials. - Authors Photography. [4]

The harmonious aspect of Feng Shui application does not only come in form of colour, because the technology that results out of the observations of the natural elements, comes with the benefit of providing a natural tattoo freed of the black ink and dyes that artificial henna tattoos use. These artificial dyes can become dangerous to the user in case of occurrence of an allergic skin reaction, due to scarification risk. [6]

\subsection{Colour in harmony}

Colour is an important factor in fashion design. "At the start of each year since the dawn of the new century, Pantone has selected a Colour of the Year. This is the shade that best encapsulates the spirit of the time, and that can be expected to pop up everywhere throughout the coming months, both in fashion and in other areas of design and daily life." [7] This is more commonly known as fashion tendencies or trends. [8]

Whatever the trend of the year is, each user has his very personal colour perception and preferences that can be defined through his psychology or physiological sensations. Heller studied relations between colour and emotion as a psychological result of cultural influence. [9] Silva clearly describes physiological reactions to colour as "colour sensations". [10]

Around the world, colours describe emotional characteristics. Melancholy is usually associated to blue, green to envy and yellow to cowardice. Yet, for the Chinese, colour has a complete different significance and application in order to achieve and acquire harmony and balance. [11]
Conceiving healthy and harmonious beachwear as a goal and applying the Oriental theme as a hole, studies about colour and their impact to the user, will be associated and respectively distributed on the Five Feng Shui Elements.

As a result, since each element is never associated with a single colour alone, a group of gradients are needed to form a sensation of the presence of a Feng Shui element through colour. The tests made with various materials (in order to obtain the desired results of suntan manipulation) showcase the Feng Shui elements through colour.

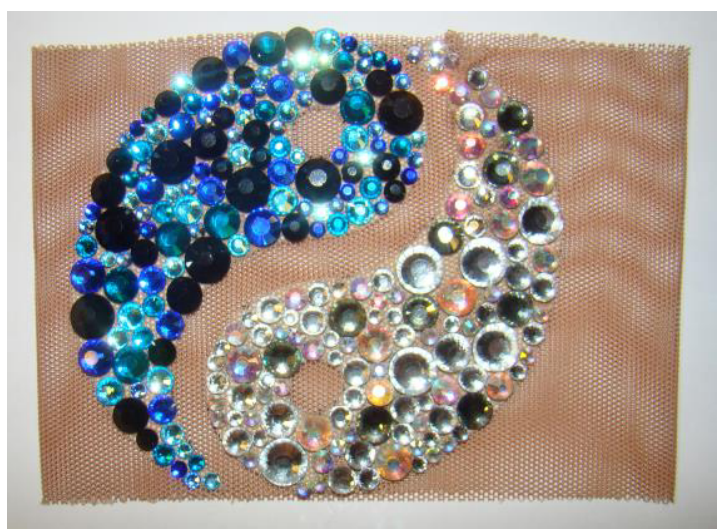

Figure 2. Yin-Yang bracelete test with gradient color interpertation. - Authors Photography. [4]

Following these principals, a bracelet was made to test the behaviour of the materials when exposed to the sun, expecting that a natural solar tattoo could come out of these material combos. The following materials were tested: Polyamid, lycra and silicone. [4] These materials not only are eco-friendly, they have proven to be functional for body art purposes.

\subsection{Environemental harmony}

With the best regards for the environment, the components from which the bracelet is made of are separable; which is a good thing when talking about recycling since the recycling process becomes much easier when components can easily be separated from each other. [12]

According to Wang, fashion products made out of multi-material composite system with detachable connection prove to be balanced in maters of recycling process and durability of the components.

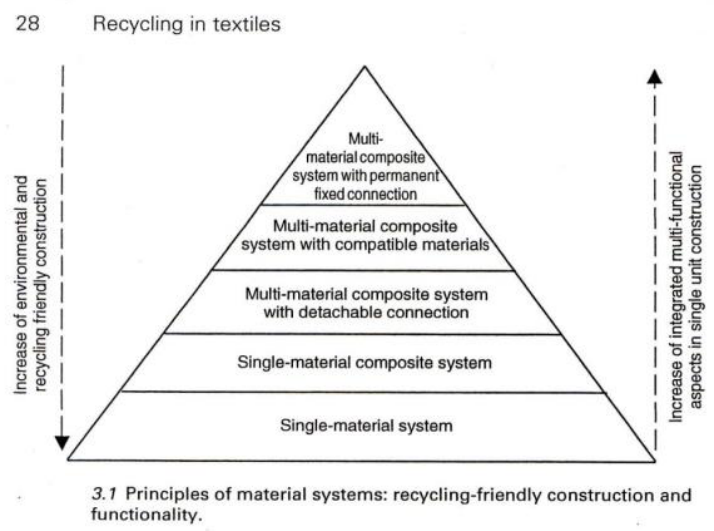

Figure 3. Wang pyramid with materials resistance in relation to materials recyclability.[13] 


\subsection{First results}

After a week of sun exposure, a natural tattoo appeared on skin, [4] as a result of material behaviour between the body and the sun, perhaps, making a new body art practice possible for the user. [14]

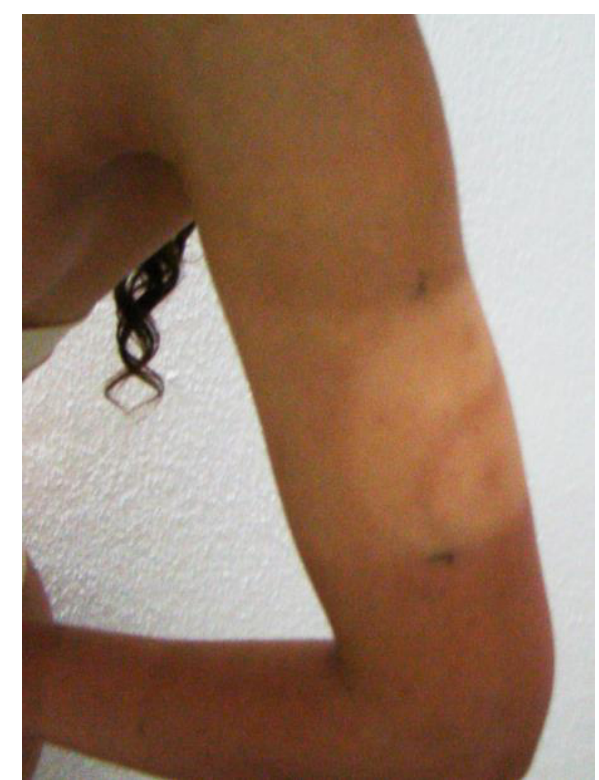

Figure 4. Test results of the Yin-Yang bracelet after its use in sun exposure.- Authors Photography. [14]

The present investigation is also dedicated to test other material behaviours that can have the same outcome in the clasp of the beachwear. Inspired by Chinese seals, this clasp is meant to be tested in acrylic.
$3 \mathrm{D}$ prints are already made and ready to come alive in other materials through mould extraction, being also possible to test with other materials that are test ready after $3 \mathrm{D}$ the printing process is over, without the need to extract moulds in order to obtain the final material intended.

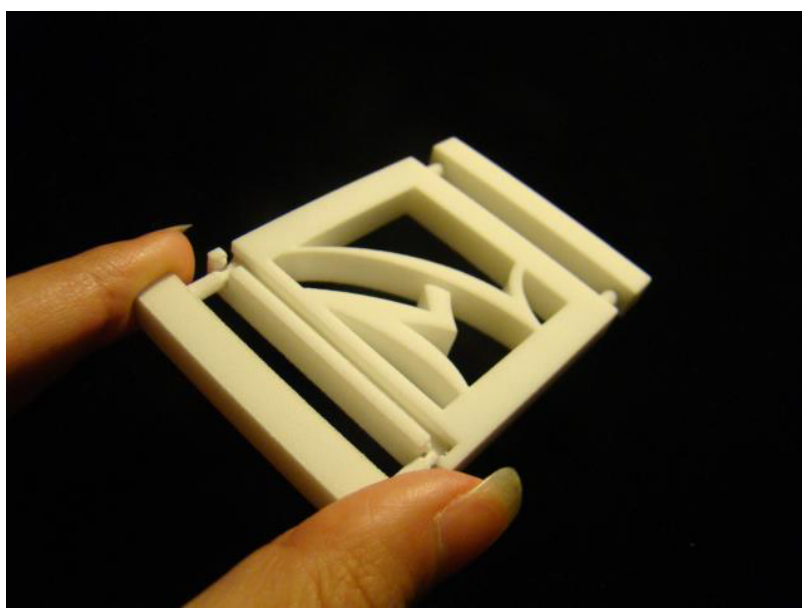

Figure 5. - 3D print of Chinese Seal Clasp.- Authors Photography. [4]

For both clasp and textile to become functional, the need of an application of a layer of silicone, on the side that comes into contact with the user's body is going to be considered and studied, in order to provide a greater adherence to the skin, allowing for a more precise tattooing of the skin by holding it in place.

It is a matter of function, and concern with the user's comfort, thus creating a product that is ergonomic and has the wearer's best interests in mind.

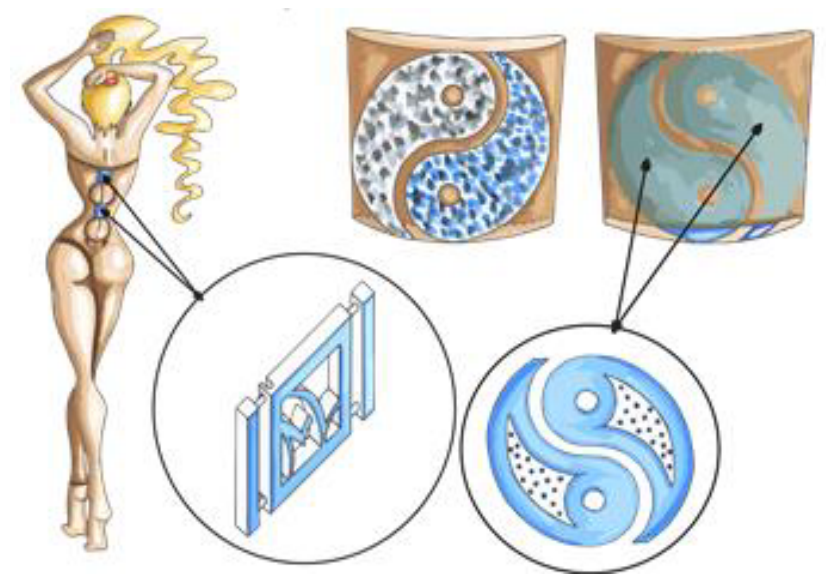

Figure 6. Silicone applications on textile and Chinese clasp.- Authors Illustration. [4]

\section{References}

1. N. Thomas: Body Art, Thames \& Hudson world of art, London, p. 12, 34, 126, (2014).

2. The Unesco Courier: A window open to the world. A lost metropolis of 4,000 years ago discovered in Syria. 2, p. 19, (1977).

3. C. Fabius: Mehndi: The Art of Henna Body Painting Thames \& Hudson world of art, London, (2014).

4. V. Mendes: Solar Wear Tattoo: Harmonia do Design de Moda, no Beachwear como Tatuagem - Fusão
Cultural, Faculty of Architecture - University of Lisbon, 55, pp. 9-11, 26-27, 2015.

5. G. Lehnert: História da Moda do século $X X$ Konemann, Germany, p. 28, (2001).

6. S. Benomar, L. Ismaili, L. Benzekri, B. Hassam: Tatouagem au henné noir: au-del'de l'eczéma de contact. Elsevier B.V., Critica Françêsa de Alergologia - Fato clinico, (2009).

7. L. Eiseman, E. P. Cutler: Pantone ${ }^{\circledR}$ on Fashion: A Century of Colour in Design, Chronicle Books LLC, San Frncisco, p. 109, (2014).

8. M. Sabino: Dicionario da Moda, Elsevier Editora Ltd, Rio de Janeiro, p. 574, (2007). 
9. E. Heller: A psicologia das cores, Editorial Gustavo Gili, SL, Barcelona, (2009).

10. F. M. Silva: A Colour Space. Its quality management in architecture. The colour/space unity as an unity of visual communication, Ph. D. Thesis, UK, (1999).

11. M. S. M. Kong: Harmonia e Proporção. Um olhar sobre o desenho arquitetónico no Ocidente e no Oriente, Inside city, Lisboa, p. 117, (2012).
12. C. Morais: A Sustentabilidade no Design de Vestuário, $\mathrm{Ph}$. D. Thesis, Lisboa, (2013).

13. Y. Wang: Recycling in textiles., Woodhead Publishing Limited \& Cr Press LLC, England, (2006).

14. V. Mendes: Solar Wear Tattoo (to be published). 